\title{
Design and Evaluation of Science Teaching Using STEM Literacy
}

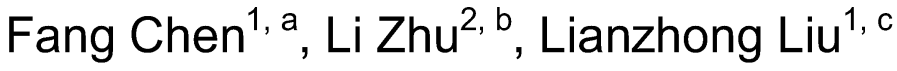 \\ ${ }^{1}$ Chongqing normal University Chongqing 400700 China \\ ${ }^{2}$ Chongqing Vocational and Technical University of Mechatronics 402760 China \\ a49403591@qq.com, b17007811@qq.com, c147448938@qq.com
}

\begin{abstract}
Objective: In this study, setting up STEM-based science teaching time activities proves the superiority and effectiveness of STEM-based scientific teaching design. It can provide guidance and reference for the implementation of STEM curriculum in China. Methods: By collecting and consulting a large number of relevant literatures on this aspect, in this study, they are analyzed and summarized, and the core content and key elements of STEM education are studied, so as to lay a good foundation for the follow-up teaching design and practice. Then, the teaching steps are designed, the literacy framework and the teaching mode are established, and finally the teaching practice is carried out. Through teaching practice, the effect of STEM teaching mode is verified and analyzed. Results: Through practical activities, it is concluded that the teaching practice activities based on STEM educational concept can effectively promote the development of students' personal interests, especially for the interest under the influence of the situation. Moreover, it can effectively promote the development of students' personal scientific literacy, especially the practical ability of students' scientific practice. Conclusion: Scientific instructional design based on STEM literacy plays an important role in improving students' overall personal qualities and can be widely used in teaching.
\end{abstract}

Keywords: STEM literacy, multidisciplinary integration; teaching mode; scientific literacy.

\section{Introduction}

Due to the continuous development of the national education reform, the new curriculum reform is also progressing [1]. In recent years, the most important core of the new curriculum reform is curriculum integration. In the wave of reform, the science curriculum in junior middle school in China has changed from division to synthesis, which is a sign of transformation to integration. However, how to truly achieve curriculum integration has become a focus and difficulty [2]. Among them, the proposal and development of STEM education has brought new opportunities and challenges to China's education. Its proposal has made many experts and scholars at home and abroad carry out in-depth research on this issue, bringing new vitality to the cause of education, and promoting the transformation and development of the cause of education [3].

STEM education originates in the United States. It integrates science, technology, engineering and mathematics $[4,5]$. The original purpose of the proposal is to promote the integration of multiple disciplines, strengthen the close relationship between disciplines, break the relatively independent state of each discipline, and encourage students to use the knowledge of multiple disciplines to explore and solve problems, cultivate their thinking ability and pursue the spirit of science $[6,7]$. Its main feature is that it pays more attention to students' ability to design and solve problems. The educational reform plan and development concept issued by the Ministry of Education of China conform to its core content. The aim of the concept of "people-oriented, promoting quality education" is to improve students' overall thinking ability, practical ability, exploring and finding problems and solving problems. The application of STEM education in teaching design is of great significance to students' individual, overall education and scientific undertakings $[8,9]$.

In this study, by collecting and reviewing a large number of relevant literatures on this aspect, it is analyzed and summarized, the core content and key elements of STEM education is studied, so as to lay a good foundation for subsequent teaching design and practice. Then, the teaching steps are designed, the literacy framework and the teaching mode are established, and finally the teaching practice is carried out. Through teaching practice, the effect of STEM teaching mode is verified and 
analyzed. Through this study, it can be seen that the teaching method based on STEM education can effectively improve students' interest in learning and scientific literacy, and play an important role in students' personal development and the development of education and scientific undertakings.

\section{STEM Literacy}

\subsection{Definition of STEM Literacy Concept}

For the concept of STEM literacy, there are two main ways of saying, "competence theory" and "way theory". The theory of competence regards STEM literacy as the ability to identify, integrate and apply conceptual and principled complexity problems in science, technology, engineering and mathematics and to solve them creatively. This definition is more common in domestic and foreign literature, and it is in line with the general idea of conceptual research. However, Zollam, a scholar at the University of North Illinois, believed that STEM literacy should not be regarded as a content area, but as a way to acquire deeper learning (including skills, abilities, factual knowledge, procedures, concepts and metacognitive abilities). That is to say, "learning for STEM literacy" changes to "using STEM literacy for learning".

Since STEM education in China is in its infancy, it is more appropriate to understand STEM literacy as a necessary ability for students in the 21 st century. Only when the students' foundation is solid and their ability develops to a certain stage, can STEM literacy become the "tool" of students' learning naturally. Combined with the previous analysis of the concept of literacy, in this study, STEM literacy is considered to be a comprehensive expression of one's own knowledge, thinking, ability and attitude when dealing with STEM problems. That is to say, it can integrate the knowledge, thinking and skills of science, technology, engineering, mathematics and related fields to solve the real STEM problems. In addition, on this basis, a correct understanding of STEM in various fields of the objective world and social impact attitude is formed.

\subsection{Composition of STEM Literacy}

From the point of view of existing research, the majority of STEM literacy is understood from the perspective of STEM disciplinary decomposition, especially the domestic analysis of the content of STEM literacy. Although this way of understanding can summarize comprehensively what subject literacy STEM education should focus on, the shortcoming is that it does not well reflect the integration and integration of STEM education. STEM literacy should be the product of the synergy of science, technology, engineering, mathematics and other four disciplines, and its effect is far greater than the sum of the four disciplines. How to integrate the subject literacy of STEM in four fields according to the current situation and development requirements of students' literacy in China, and summarize a set of literacy framework or standards suitable for STEM education and training system in China, is exactly the most important issue that needs to be paid attention to in the field of relevant education research in China at present. As shown in figure 1, it is mainly composed of scientific literacy, technical literacy, engineering literacy and mathematical literacy. 


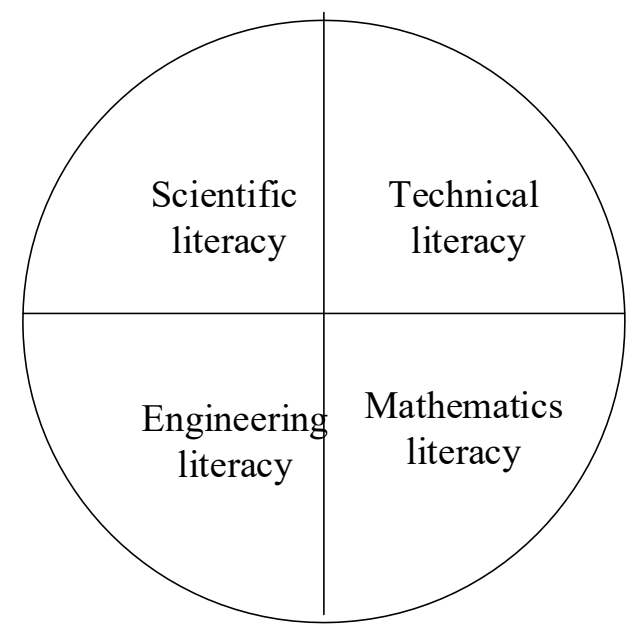

Figure 1. Composition of STEM literacy

\subsection{Construction of STEM Literacy Framework}

Based on STEM elements and combined with the reality of primary and secondary school students, the STEM literacy framework is proposed and constructed. As shown in figure 2, it mainly consists of STEM knowledge, STEM thinking, STEM ability and STEM attitude. It should be noted that in the specific educational practice, not every STEM course will involve all the above STEM literacy. Different types of STEM courses have different emphasis, so there are also differences in ability training and training. Of course, when developing STEM courses, teachers or relevant institutions should closely adhere to STEM literacy to prepare and design relevant content, so as to maximize students' STEM literacy.

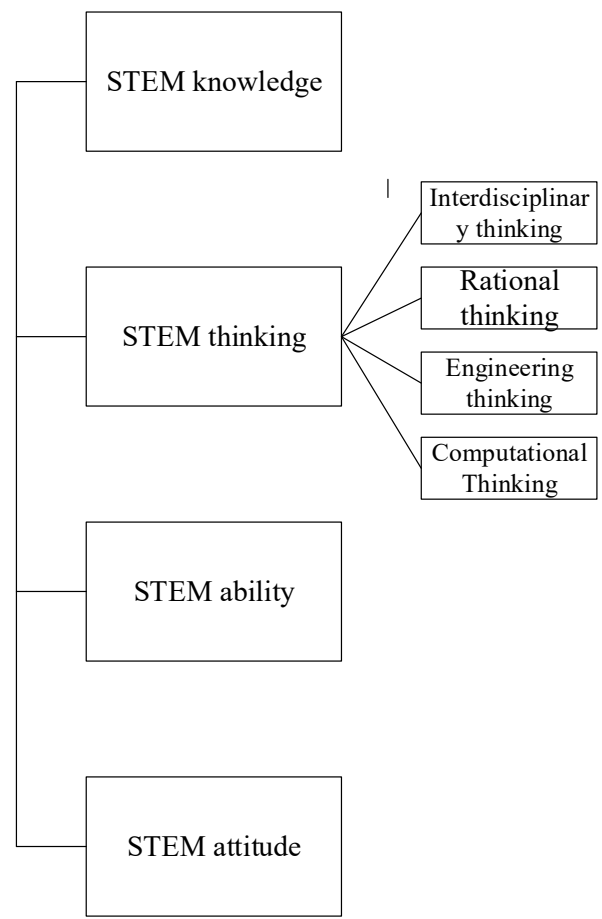

Figure 2. Construction of STEM literacy framework

\subsection{STEM Teaching Procedure and Model Construction}

Based on the analysis of the five elements of STEM teaching, and according to the principles of objectivity, scientificity, operability and conciseness of the model construction, the STEM teaching model chart is designed, as shown in figure 3. 


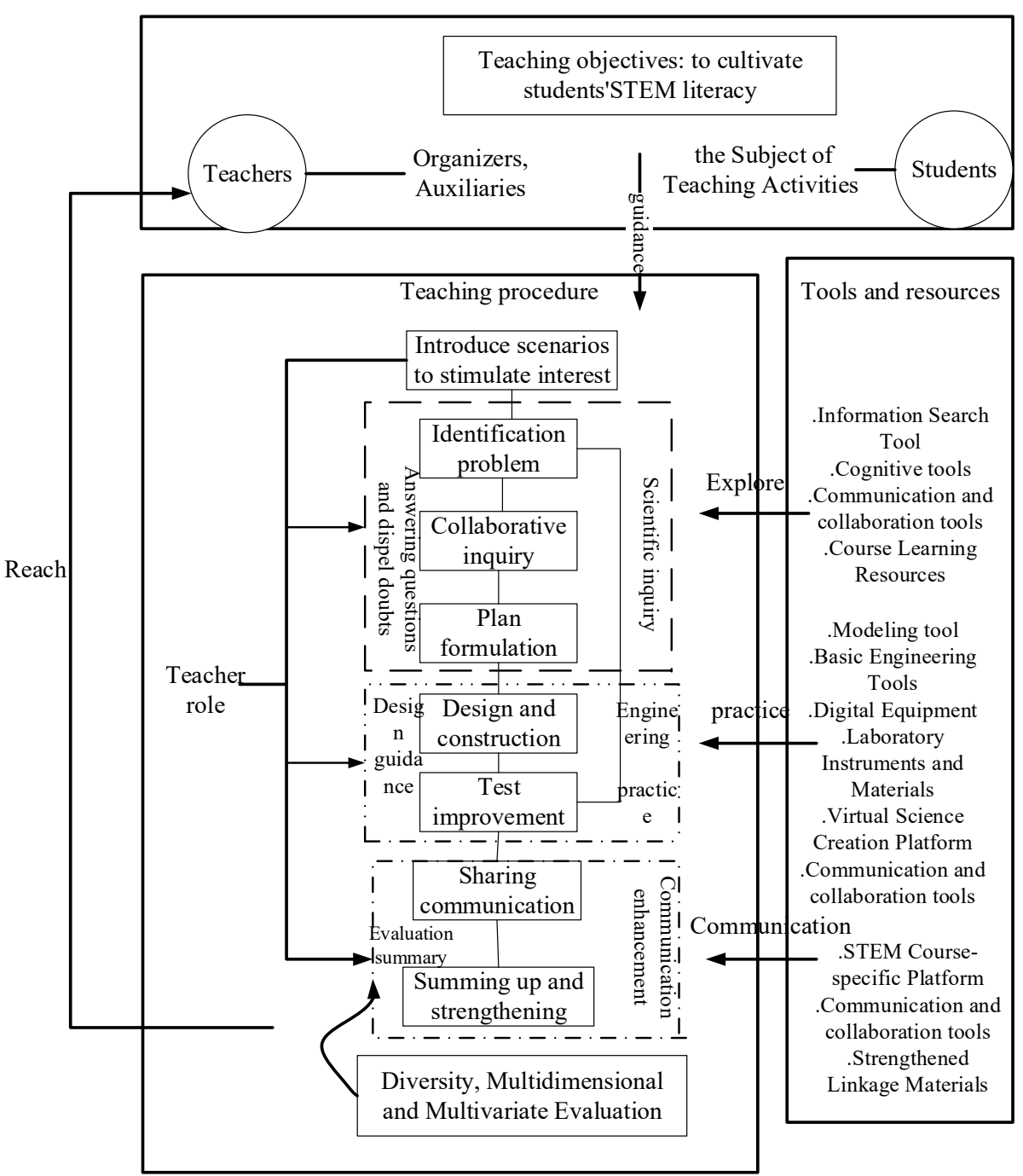

Figure 3. Teaching mode chart based on STEM

\subsection{STEM Teaching Evaluation}

Teaching evaluation is a test of the achievement of teaching objectives and a judgment of the teaching effect of teachers and students. Feedback information obtained through teaching evaluation can well guide and improve teaching. According to different standards or bases, teaching evaluation can be divided into different types. Generally speaking, the common evaluation methods are as follows.
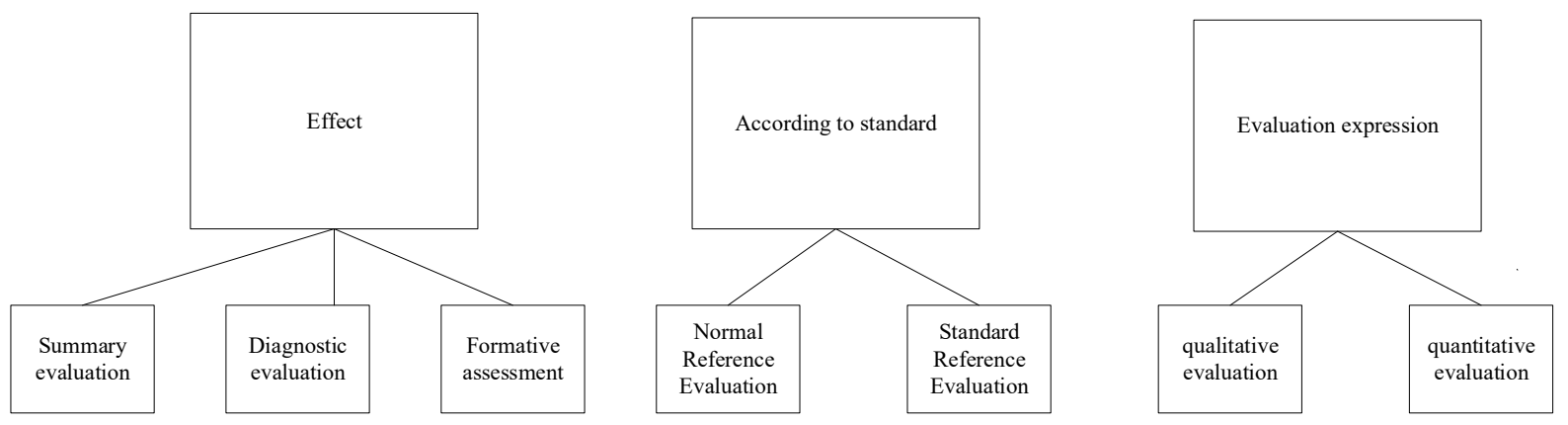

Figure 4. STEM teaching evaluation method

In traditional teaching, due to the excessive emphasis on knowledge imparting in the classroom, teaching evaluation is also very important, mainly to test the students' knowledge mastery and the summative evaluation of the standard situation as the core. The obvious disadvantage of this 
evaluation method which only focuses on learning results is that it is difficult to detect the development of students' emotional attitudes, learning strategies and so on in the learning process, and cannot make a comprehensive evaluation and measurement of students' learning effects. STEM teaching evaluation should change the previous single evaluation model, adopt a variety of ways, from multiple dimensions, multiple angles to evaluate students' learning situation, teachers' teaching situation and so on. According to the general thinking of educational evaluation research, combining the characteristics of STEM course and educational idea, in this study, the evaluation system of STEM teaching mode is mainly introduced from the aspects of evaluation method, evaluation content and evaluation subject.

\section{STEM Teaching Practice}

In this study, the "water purification" is taken as a teaching topic, and teaching practice activities based on STEM educational concept are carried out. Taking students' interests and scientific literacy as the research focus, in this study, the changes of students' interests and scientific literacy after the teaching practice activities based on STEM educational concept are studied, to verify the validity of evaluating the teaching practice based on STEM educational concept.

\subsection{Teaching Object}

In this study, 72 students in the fifth grade ordinary class of XXX primary school are taken as the object of practice. Among them, the total number of each class is the same, 36 people. The ratio of men to women is the same, with 18 boys and 18 girls in each class. One of the classes is the control group, which receives traditional teaching activities. The other class is the experimental group, which receives the teaching practice activities based on STEM educational concept.

\subsection{Teaching Procedures and Classification of Activities}

The teaching steps are designed. The first step is to communicate with students and discuss basic information about water resources and their applications. Through discussion, students' interest in this aspect is stimulated. Secondly, the students are made to learn by themselves, make use of the resources on the Internet to understand the knowledge about this aspect, draw the flow chart of water purification by themselves, and learn the method of engineering design. Finally, the case analysis method is applied to realize the knowledge of water purification in different countries around the world, so that students can analyze and integrate the information by themselves, and improve the ability of information application. Activity partitioning is shown in figure 5 .

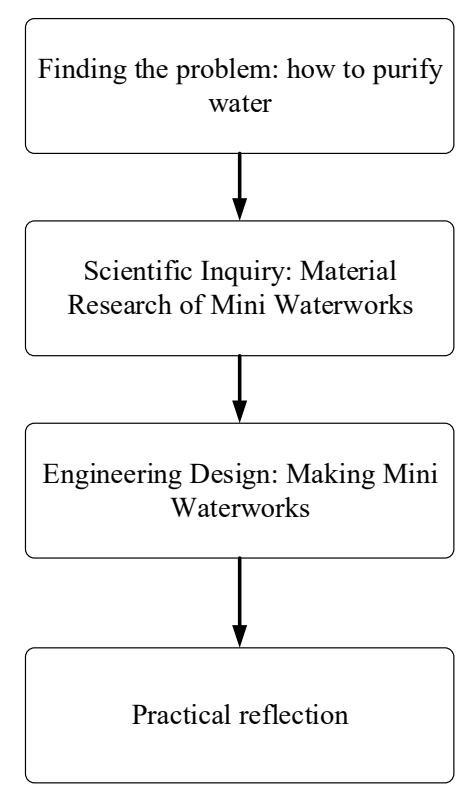

Figure 5. Classification of teaching activities 


\section{Practical Results and Analysis}

In this study, the data of the questionnaire of pupils' interest in scientific learning and the evaluation form of pupils' scientific literacy are analyzed and collated to analyze and compare the overall dimension of scientific literacy and hobby level between the experimental group and the control group, and to explore whether the teaching practice based on STEM educational concept is useful for the cultivation of students' personal interests and the improvement of their scientific literacy.

\subsection{Analysis of Primary School Students' Interest Appreciation Scale}

In this study, the students' personal interest and situational interest after they accept the teaching practice activities based on STEM educational concept are evaluated by using the questionnaire of pupils' interest and hobby. The evaluation criteria are set at 1 to 5 points. The standards are totally inconsistent, comparatively inconsistent, general, comparatively consistent and completely consistent, respectively. The higher the score is, the higher the level is. The total number of valid questionnaires is 72,36 in each group. The results are as follows:

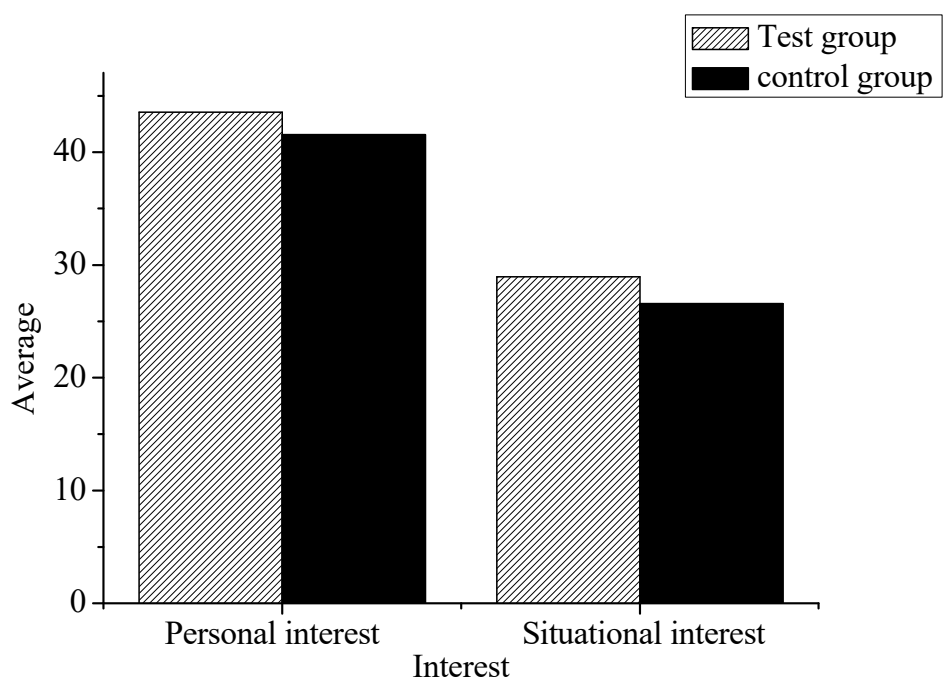

Figure 6. Results of the primary school students' interest appreciation table

According to figure 6, it can be seen that the interest level of the students in the experimental group is higher than that of the control group. Among them, the growth of the level of situational interest is higher than that of personal interest. The gap of situational interest is 2.36 , the growth rate is $8.88 \%$, the gap of personal interest is 2 , and the growth rate is $4.81 \%$. It can be known that the teaching practice activities based on STEM educational concept can effectively promote the development of students' personal interests, especially for the interest under the influence of the situation.

\subsection{Analysis of the Results of Scientific Literacy Evaluation Table for Primary School Students}

In this research, the students' scientific knowledge and scientific practice after they accept the teaching practice activities based on STEM educational concept is mainly evaluated by applying the primary school students' scientific literacy evaluation table. Each group is divided into six groups on average, with evaluation criteria ranging from 1 to 4 . The higher the score is, the higher the level is. The total number of valid questionnaires is 12, with 6 in each group. The results are as follows:

Table 1. Average score of scientific literacy evaluation table for pupils of two groups

\begin{tabular}{|c|c|c|c|c|}
\hline Category & Experimental group & Control group & Disparity & Growth rate \\
\hline Scientific knowledge & 2.5 & 2.17 & 0.33 & $15.21 \%$ \\
\hline Scientific practice & 21 & 12.83 & 8.17 & $63.68 \%$ \\
\hline
\end{tabular}




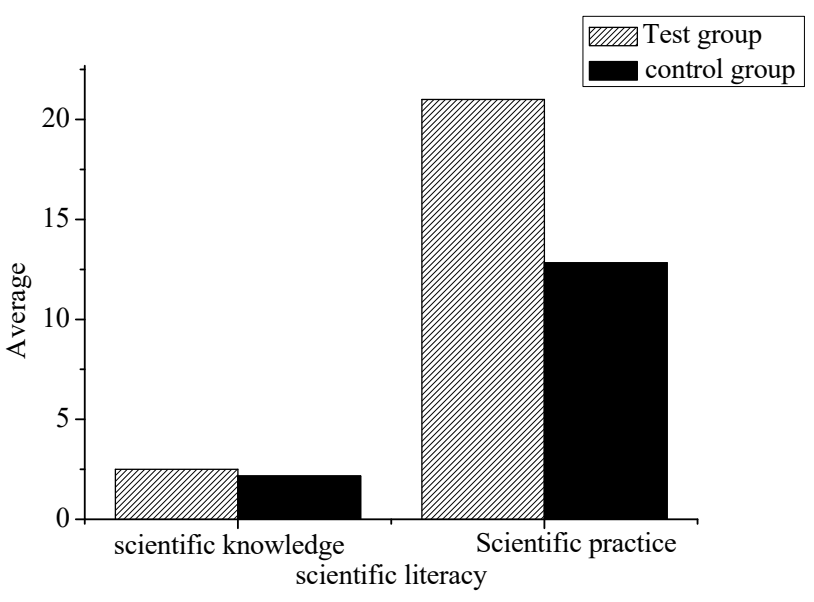

Figure 7. Analysis of the results of the primary school students' scientific literacy evaluation table

According to figure 7, the students in the experimental group have higher scientific knowledge and scientific practice literacy than those in the control group. Among them, the growth of scientific practice level is higher than that of scientific knowledge. The gap between scientific practice and practice is 8.17 , the growth rate is $63.68 \%$, the scientific knowledge is 0.33 , and the growth rate is $15.21 \%$. It can be known that the teaching practice activities based on STEM educational concept can effectively promote the development of students' personal scientific literacy, especially the practical ability of students' scientific practice.

\section{Conclusion}

With the continuous development of education, society can make progress and the country can become stronger and stronger. There is a close relationship between the development of education and the cultivation of talents for a country to become stronger. China needs to constantly adapt to social development to reform education and teaching, constantly improve students' scientific literacy and practical innovation ability, promote the development of education and scientific and cultural undertakings, and improve the overall soft power.

In this study, by collecting literature, the core content and key elements of STEM education are studied, teaching steps based on STEM education are designed, literacy framework and teaching mode are established, and finally teaching practice is carried out to verify and analyze the effect of the teaching mode of applying STEM education through teaching practice. Through the teaching practice, it can be seen that the teaching method based on STEM education can effectively improve students' interest in learning and scientific literacy, improve students' practical ability, innovative ability, independent thinking ability, and the ability of multi-disciplinary comprehensive application, which plays an important role in students' personal development and the development of education and science.

\section{Acknowledgments}

Chongqing's 13th Five-Year Plan for Educational Science, the key topic of 2018, "Research on the Design and Evaluation of Scientific Teaching Based on STEM Literacy" (2018-GX-110).

\section{References}

[1]. Hao, Li-Jun|Xiao, Zhe-Tao. Research on Information-Based Teaching in Reform and Practice of Architectural Design[J]. Eurasia Journal of Mathematics Science \& Technology Education, 2017, 13(7). 
[2]. Çetinkaya, Murat. Design of Personalized Blended Learning Environments Based on WebAssisted Modelling in Science Education[J]. International Journal of Evaluation \& Research in Education, 2016, pp. 5.

[3]. Cardiel C L B, Pattison S A, Benne M, et al. Science on the Move: A Design-Based Research Study of Informal STEM Learning in Public Spaces[J]. Visitor Studies, 2016, 19(1), pp. 39-59.

[4]. Kastens K, Krumhansl R. Identifying Curriculum Design Patterns as a Strategy for Focusing Geoscience Education Research: A Proof of Concept Based on Teaching and Learning with Geoscience Data[J]. Journal of Geoscience Education, 2017, 65(4), pp. 373-392.

[5]. Wen J. Research on Effect Evaluation of Physical Education Teaching Based on Artificial Intelligence Expert Decision Making System[J]. 2016.

[6]. Repenning A, Webb D C, Koh K H, et al. Scalable Game Design: A Strategy to Bring Systemic Computer Science Education to Schools through Game Design and Simulation Creation[J]. Acm Transactions on Computing Education, 2015, 15(2), pp. 29-31.

[7]. Follette K B, Mccarthy D W, Dokter E, et al. The Quantitative Reasoning for College Science (QuaRCS) Assessment, 1: Development and Validation[J]. Physics, 2015, pp. 8.

[8]. Colwell J, Enderson M C. "When I hear literacy": Using pre-service teachers' perceptions of mathematical literacy to inform program changes in teacher education[J]. Teaching \& Teacher Education, 2016, 53, pp.63-74.

[9]. Chiappinelli K B, Moss B L, Lenz D S, et al. Evaluation to Improve a High School Summer Science Outreach Program[J]. Journal of Microbiology \& Biology Education, 2016, 17(2), pp. 225-236. 